\title{
Reconnecting people, place, and nature: examining alternative food networks in Newfoundland's fisheries
}

\author{
Chloé Poitevin DesRivières ${ }^{1 *}$, Ratana Chuenpagdee ${ }^{2}$ and Charles Mather ${ }^{2}$
}

\begin{abstract}
Background: Fisheries have played a significant role in the economic development of Newfoundland and Labrador and continue to contribute to coastal livelihoods and local food security. However, the access to and availability of locally harvested fish and seafood in the province is notably lacking, particularly since federal and provincial policies have prioritized the development of export markets in the fisheries over local sales. In this paper, we examine market actors and civil society organizations in St. John's (the provincial capital) and Petty Harbour (a nearby fishing community) that have embarked on initiatives to better include fish and seafood in the local food system. The success of these initiatives depends in part on the degree of connectivity between consumers and harvesters, as well as between people, the culture of fishing, and the marine environment.

Results: Reconnections are the foundations of alternative food networks (AFNs), which aim to develop more environmentally and socially sustainable and localized ways of producing, distributing, retailing, and consuming food. This paper explores the social, cultural, and ecological values of the fisheries as means to forging reconnections. The research reveals that values pertaining to traditional food culture, environmental stewardship and conservation, localization, and social cohesion were significant motivating factors for stakeholders in seeking out reconnection in their food system.
\end{abstract}

Conclusions: While AFNs in Newfoundland's fisheries are currently underdeveloped, reconnections are nonetheless taking place along the fisheries supply chain and can contribute to enhancing the accessibility and availability of locally harvested fish. The study also finds that AFNs must be context appropriate and reflect local values, as there are significant opportunities in building on Newfoundland's strong fishing culture and heritage.

Keywords: Alternative food networks, Fisheries, Values, Reconnection

\section{Background and rationale}

Alternative food networks (AFNs) have arisen within the food movement as practical and localized responses to growing concerns over the wide-ranging socio-economic, cultural, and environmental impacts of conventional food production. In addressing the shortcomings of conventional food systems, AFNs seek to create shortened and localized supply chains in order to enhance consumer awareness about where their food comes from

\footnotetext{
*Correspondence: chloe.poitevin@carleton.ca

1 Department of Geography and Environmental Studies, Carleton

University, Ottawa, ON, Canada

Full list of author information is available at the end of the article
}

and develop alternate means of producing, distributing, and retailing food [1]. AFNs were shaped by concerns over agricultural food production; however, they are equally relevant to the diverse and complex challenges faced in fisheries-based food systems. Much like industrial agriculture, commercial fisheries are part of a highly globalized, technology-driven, and resource-intensive food system. The advent of highly efficient catch methods has resulted in the overexploitation and degradation of marine resources, particularly in the light of a rising global demand for fish and seafood $[2,3]$.

Lengthening supply chains are of equal concern in the fisheries, in which consumers and fish harvesters have 
become increasingly distanced both socially and geographically [4]. The notion of disconnection highlighted by AFN literature can provide insight into ways to localize and simplify fisheries food systems. While local and sustainable food movements have seldom included fisheries, certain approaches derived from agricultural contexts have been adapted to enhance consumers' access to locally sourced and sustainably caught fish $[4,5]$. With the emergence of AFNs that include fish and seafood, there remain significant questions with regard to how these fisheries AFNs operate and are structured, especially given that the institutional, socio-cultural, and economic contexts of fisheries are vastly different from those of agricultural food systems [6].

This research examines ways in which fisheries AFNs may present sustainable and appropriate alternatives to conventional fisheries harvest, marketing, and consumption practices in two locations in Newfoundland: the St. John's metropolitan area and the nearby fishing community of Petty Harbour-Maddox Cove (henceforth Petty Harbour). In the following section, we present the AFN concept of 'reconnection' and assess the extent to which it exists in Newfoundland. Next, we describe the study locations and research methods, followed by the main findings. In this analysis, care ethics and the interactive governance perspective inform an understanding of the ways in which the values and ethical motivations that guide decision-making processes enable reconnections in AFNs. We conclude with a discussion about opportunities and limitations in developing fisheries AFNs in contexts similar to Newfoundland and elsewhere.

\section{Reconnecting through alternative food networks}

Critical understandings of AFNs evoke a broad definition and appearance of 'alternative foods' to reflect the diverse contexts in which alternatives take place, rather than simply presenting 'alternative' in a dichotomous opposition to conventional food production [1, 7-9]. Conventional food systems have largely been framed as 'bad', particularly since associated food production processes generate significant ecological issues, including habitat degradation and loss of biodiversity; and sociocultural and economic issues, such as the homogenization of food cultures and the concentration of power in the hands of a few corporate entities $[1,10]$. Despite the many failings of global conventional food systems, it is problematic to assume that alternative food strategies and networks are intrinsically sustainable. The variability in alternative food practices has given considerable weight to the significance of the term 'alternative', particularly since many originally 'alternative' approaches have been absorbed into mainstream and industrial practices [11].
One potential answer to the question of what makes AFNs 'truly' alternative can be found in the concept of 'reconnection'. Reconnection has become a central notion in many leading AFN discourses and actions, given that the connection between the different actors throughout the supply chain is one of the key drivers behind direct marketing schemes and other alternative food initiatives $[7,12]$. In accounting for the complex social and natural systems and governing institutions that shape food systems, reconnection as part of AFNs is best viewed as a process that produces varied relations and outcomes [13, 14]. Therefore, reconnection can be economically motivated due to the fact that producers seek to enhance localized market opportunities and add value to their products, although they can also be motivated by a desire to create an ethical and ecologically sustainable food system [14].

These multifaceted rationales for reconnection in food systems are linked to conceptions of moral economies through 'care ethics', which refers to personal concerns and care for ecosystems, culture, local economy, sustainability, and local communities [13]. In this concept, the economy is understood as performative in that it is a part of and produced by social relations, rather than a wholly separate entity $[15,16]$. A moral economy is an attempt to rework and challenge the ways in which relations of economic exchange are perceived as enacted by rational actors in the pursuit of profit maximization [15, 17]. Alternative economic possibilities, such as AFNs, include ethical considerations as part of economic relations, thus offering a means to examine interpersonal and economic relations in food systems and fisheries as guided by values and ethics, rather than presumed individualistic self-interest $[15,18]$. In this sense, economic choices and preferences are understood as the combined result of behaviours that are learnt through social and economic institutions and transmitted by culture and society by means of personal relationships $[17,19]$.

In AFNs, food choices are based both on self-interest, including enjoyment, health, and nutrition, and on outward cares and concerns, such as care for others, the local community, and the natural environment [13]. Although these cares are central to the AFN model, consumers are nonetheless constrained by economic factors and are not always able to make food choices based on individual tastes and moral preferences [20]. The concept of reconnection allows for an examination of the values that affect people's food choices, which leads to a better understanding of how AFNs emerge and what motivates people to participate in alternative practices in their food system.

While the motivations for seeking alternatives in fisheries-based food systems bear similarities to those 
in agriculture, there is a need to understand the differences in the social, biological, and governing systems that create a new and unique set of challenges for this food system. In this light, the idea of 'reflexive localism' is especially important for defining locality in a way that takes context into account and is receptive to change [1]. Reflexive localism is process oriented, in the sense that localization is not an end goal but a continually evolving set of relations between different actors and at different scales. Notions of place making and sense of place are useful in understanding the ways in which people relate to landscapes and places, and how these may impact localization processes. In particular, place is created and recreated through different food practices, cultures, and physical geographies [21].

Landscapes, particularly physical geographic realities such as soil composition, weather, and topography, shape food cultures and localization processes through the biophysical limits imposed on how and what foods can be produced or caught [21]. It is equally important to consider temporal scales, since 'local' foods conceptually include the adoption of a seasonal diet, which can limit the choices and availability of fresh produce throughout the year depending on climate [22]. Both the geographic and temporal scales of fisheries are different from agriculture, and many regions are simply not located in areas that can support commercial fishing [12]. While biological factors, such as seasonal migrations and spawning, play a role in determining the availability of fish and seafood, fisheries management regulations determine when and how much fish can be caught.

\section{AFNs and fisheries in Newfoundland}

Fisheries in Newfoundland and Labrador hold an immense cultural and historical significance and are highly complex in terms of actors, institutions, and ecology. The province's cultural identity and historical economic development are intrinsically linked with the fisheries, particularly with respect to Atlantic cod [23]. Newfoundland's fishery has gone through dramatic changes and challenges in the last century, specifically with the collapse of the commercial cod fishery in 1992, following nearly 50 years of intensive overfishing [24]. While the subsequent moratorium on the commercial Atlantic cod fishery significantly impacted coastal communities and livelihoods, fishing continues to be an important source of revenue and employment in the province. Snow crab and shrimp have replaced cod as the primary commercial and export species, currently accounting for $83 \%$ of capture fisheries' landed value, and have become more lucrative than the cod fishery was prior to the collapse $[25,26]$. There remains a restricted commercial quota for Atlantic cod and a limited recreational cod fishery $[25,26]$.

More recently, the sustainability and durability of the Northern shrimp fishery has been brought into question, as shrimp stocks have been in decline since the 2000s due to increased catches and unfavourable environmental conditions [27]. There is also a push to re-establish the cod fishery, with some evidence pointing to the recovery of Atlantic cod stocks [26]. Other significant challenges to the fishery include a shrinking workforce due to ageing and outmigration, which is exacerbated by the seasonal, economically prohibitive, and often-insecure nature of fishing employment that discourages new entrants [24, 25].

The development of a resilient and sustainable local food system is vital to ensuring food security, particularly in rural communities in Newfoundland, due to the geographic isolation of the island, which presents significant challenges to residents' access to nutritious, affordable, and culturally appropriate foods. In fact, the majority of fresh fruits and vegetables consumed within the province are imported from mainland Canada or internationally, which can lead to food shortages as food distribution networks are vulnerable to interruptions such as natural events that prevent shipping $[28,29]$. The access to and availability of fresh, nutritious foods is further challenged by the remoteness of many rural coastal communities, where residents often face lengthy travel times to the nearest full-service grocery store [29].

Although AFNs in the fisheries are developing in many coastal communities in Canada, they have been particularly slow to emerge in Newfoundland and Labrador compared to other coastal provinces. Efforts to introduce fisheries AFNs in Canada mostly come in the form of community-supported fisheries (CSFs), which aim to create a guaranteed local market for fishers and a source of fresh and sustainable fish for consumers. Notable CSFs in Canada include Off the Hook in Halifax, Nova Scotia and Skipper Otto's in Vancouver, British Columbia. While AFNs in Canadian fisheries are still underdeveloped, the number of AFNs in Newfoundland's agricultural systems has increased, with a growing network of farmers' markets and direct marketing schemes for agricultural products. In addition, there is a rich history of self-provisioning practices, including fishing, gardening, hunting, and berry picking, that have contributed significantly to food security [28, 30]. These practices, and other types of informal labour, hold culturally and economically significance for many in Newfoundland, particularly people residing in remote rural areas, such as the many small fishing communities in the province [31]. The seasonal nature of fisheries economies and the strong social ties in these communities, as well as their geographic isolation, 
create a strong role for informal economic networks as a key means to ensure livelihoods and food security for many residents $[28,31]$.

Significant barriers exist in the form of provincial and federal legislation, which restrict the development of alternate and informal markets [32-34]. In particular, both the federal and provincial fisheries governing bodies, the Department of Fisheries and Oceans (DFO) and Department of Fisheries and Aquaculture (DFA), respectively, have neglected the development of local markets for fish and seafood, instead focusing heavily on exportoriented production [25]. Equally, the access to and availability of locally harvested fish was further limited by competing interests in the fisheries, primarily between fishers and fish processors and workers [33]. The direct sales of fish-by-fish harvesters were prohibited in Newfoundland and Labrador until late 2015, justified on the grounds of maintaining the viability of the fish-processing industry and to ensure food safety [33]. Despite strict provincial regulations, a handful of alternative food efforts emerged to increase the availability of locally sourced fish and seafood.

Fisheries regulations and policies are also impacted by the Fish, Food and Allied Workers Union (FFAW-Unifor), an important lobbying group in the province that is active in developing local market opportunities, which the union see as an important means to support inshore fish harvesters. The FFAW-Unifor are also committed to developing external markets for Newfoundland fish and seafood in an effort to support the interests of their diverse membership, which includes large-scale fishing operations and fish plant workers in addition to smallscale inshore fish harvesters.

The geographic focus of the study is on the St. John's metropolitan area and the community of Petty Harbour, located both on the Avalon Peninsula and on the east coast of the island. These cases offer an opportunity to examine emerging alternatives, in terms of how they arise, organize, and operate.

St. John's is the capital of Newfoundland and Labrador and is the province's most densely populated area, with the metropolitan region hosting a population of approximately 200,000 [35]. St. John's serves as the province's economic and administrative centre, with the tourism and the offshore petroleum industries generating significant revenue within the city. The local and sustainable food movement has become increasingly prominent in St. John's, with a number of agriculture-oriented AFNs developing in the region, including direct farm sales, community-supported agriculture (CSA), and farmers markets [36]. In terms of fisheries, there is a growing network of food businesses and other actors looking to include and promote local and sustainable fish, and many of these groups have gained public attention through their efforts [37]. Many food businesses have integrated environmental and ethical values and goals into their mandates [37].

Petty Harbour is an important fishing and tourism hub located $15 \mathrm{~km}$ south of St. John's. Fish harvesters in this area have a unique long-standing commitment to sustainability and stewardship practices and are actively involved in local fisheries governance [38]. An example of this mentality is the establishment of the Petty Harbour Fisherman's Co-operative, which operates as a fishing enterprise that is socially just and sustainable while reinvesting in the local community. Moreover, efforts to reconnect people with the local environment and their fishing heritage have been strengthened by the creation of the Petty Harbour Mini-Aquarium, a non-profit organization aimed at raising awareness about local marine habitats and animals, and the Island Rooms, a fisheries and Newfoundland culture education program for children and youth.

\section{Methods}

The study employed semi-structured interviews that covered a range of topics relating to the fisheries and food systems sustainability and governance in Newfoundland. This method allows the possibility to ask probing and follow-up questions and enables respondents to provide perspectives, experiences, and reflections in their own words $[39,40]$. Selected topics were drawn from the interactive governance framework, focusing particularly on the interactions within and between the different components of the food system and the fisheries [34, 41]. Interactive governance frames values as the foundation of decision-making processes, and stresses that understanding how people come to make choices is essential to understanding and improving governance processes [41].

The interview questions used in the study aimed at discerning the underlying values that govern the decisionmaking processes of actors participating in alternative food initiatives in Newfoundland's fisheries. These values were drawn from a selection of topics previously identified in fisheries governance literature by Song et al. [34]. In their study, 24 value types were identified and categorized into four value orientations, relating to perspectives on fisheries governance and decision-making processes. These value orientations make explicit the 'ethics of care' performed in fisheries, as well as AFNs. They include 'better world' values (e.g. altruistic, common good), 'good life' (personal well-being), 'personal virtues' (inner personal qualities), and 'outward aspirations' (relationships with others and objects) [34]. In addition, the interviews comprised questions in which participants outlined their roles and relationships in the fishery and/or food system, 
as well as their involvement in enhancing alternative markets, spaces, and knowledge for fish and seafood.

Respondents were selected using purposive sampling method in order to cover a range of actors engaged in alternative food practices. A total of 13 interviews were completed in the St. John's and Petty Harbour areas, each lasting between 15 and $45 \mathrm{~min}$. Participants included restaurant owners, chefs, retailers, fish harvesters, and local food promotion and conservation education organizations. Interview data were analysed thematically using NVivo 9 software (QSR International), guided partly by the categories outlined by Song et al. [34].

The interviews were complemented by an analysis of secondary data, including academic and grey literature, in particular news articles, podcasts, and documentaries, in order to provide a social, cultural, economic, and historical context to the interview data. Federal and provincial policy documents were examined to assess the roles of governing actors and institutions in Newfoundland's fisheries and identify potential barriers and opportunities for emerging AFNs.

\section{Results}

The identification of values underpinning alternative food practices aids in understanding the types of reconnections taking place, and the underlying motivations that lead people to seek these connections. Three primary value types were identified in the interviews: food system localization, social cohesion, and education and conservation.

\section{Food system localization}

The interview respondents interpreted 'local' in different ways and associated different benefits and values to the prospect of localizing food systems. However, these values pertained predominantly to developing market opportunities. The scale of 'local' in terms of Newfoundland's fisheries is considered larger than that of landbased food production. For instance, fish and seafood products originating from the whole island were referred to as 'local', while 'local' for agricultural products was generally seen as encompassing only the Avalon Peninsula. As well, fish originating from Atlantic Canada was viewed as relatively local, as they come from the same waters.

Restaurants and retailers interviewed for the study indicated reasons for choosing locally harvested fish and seafood around varied notions of quality. Most replied that local fish was preferable as the product 'hasn't travelled', thus perceived as fresh and possessing a small overall environmental footprint. Better taste, nutrition, and higher product quality were also mentioned. For instance, one restaurant owner viewed Newfoundland waters to be more 'pure and clean', resulting in better tasting fish and seafood. Certain restaurant owners also expressed a preference for purchasing fish and seafood from small-scale fishing vessels as these were viewed as engaging in more sustainable harvest methods and better product handling practices. Another motive for purchasing locally caught fish that many respondents noted was the desire to support the local economy, particularly rural fishing communities.

Despite a preference for local products, interview respondents expressed varying degrees of difficulty accessing locally harvested fish and seafood, either for their business or for personal consumption. The seasonality of fish and seafood was one reason that affected local availability of certain species, due to both biological limits and fisheries management regimes. The restaurant owners and chefs that have made local sourcing a part of their business plan change their menus according to seasonal variability, and turn to in-house methods of preservation for local fish, meats, and produce to overcome limited product availability, especially in the winter. Some respondents did note, however, that for some species, the fishing seasons enforced by DFO are too restrictive and do not align with the province's tourism season (which generally runs from June until September). This mismatch applies particularly to halibut and lobster, which means that restaurant owners either have to resort to frozen product, in the case of halibut, or imports from the mainland, as with lobster.

The export-oriented fisheries policy in Newfoundland was another reason frequently listed as a cause of limited access and availability to locally harvested fish. Nonetheless, export was perceived as a necessity, with one fisher based out of Petty Harbour, stressing that export was necessary to make a living. The fishers interviewed noted that the species with the highest local demand is cod, although quotas and seasons are very restricted, resulting in low profitability. The main species harvested by the Petty Harbour Fisherman's Co-op, particularly crab and capelin, are of high value on the export market, while respondents feel that the local demand simply is not there.

The one species that all of the restaurants and retailers interviewed reported no issues accessing locally was cod. Rather, it is the access to other species, such as whelks, squid, crab, and octopus, which are caught locally and destined for foreign markets or for use as bait, that pose a significant challenge to local consumption. The restaurants in St. John's were limited only to what was available through their suppliers, since they could not purchase fish directly from harvesters as per provincial regulations at the time of the interviews. Product availability was further restricted by minimum processing requirements, 
which are implemented by DFA to support the fishprocessing industry, which dictate in what form fish and seafood can be sold. In fact, many restaurants found it difficult to access whole, unprocessed fish. In the words of one restaurant owner and chef: 'A lot of our work is in the sourcing of the product than [the] preparations. Half the work is actually finding it'.

\section{Social cohesion}

The most important value identified throughout the interviews was that of social cohesion, which refers to the processes of social connection, interpersonal relationships, and community values [34]. One respondent noted that the considerable disconnection between consumers and fish harvesters in Newfoundland has impeded the flow of information about how fish gets from ocean to plate. The motivations of respondents to seek personal relationships are focused on increasing the knowledge about the product itself and the processes of harvesting fish and seafood. There is limited, if any, information available to retailers, chefs, and consumers about where, how, and by whom fish is caught, thus impeding traceability. An opportunity for creating social connections, albeit at a distance, is the seafood traceability project headed by the FFAW-Unifor on the west coast of the island. This initiative, adapted from Ecotrust Canada's ThisFish project, allows consumers to connect with fish harvesters on an online platform by means of a traceable tag on fish and seafood products. The group of restaurants in St. John's seeking to access the traceable fish see this approach as an opportunity to engage consumers with their food and the fishery and feel that, to a limited degree, the project may help in creating social connections between fish harvesters, restaurants, and consumers.

With an increasing network of alternatives in the agricultural sector in Newfoundland, restaurateurs and consumers are becoming able to build personal relationships with local food producers. Restaurants in St. John's are able to purchase directly from both local farmers and licensed hunters, and owners expressed a desire to connect in the same ways with fish harvesters: 'We can develop relationships with all kinds of farmers, all kinds of producers of everything, and I have a personal relationship with them, but I can't have a personal relationship with my fisherman', said a restaurant owner.

Another restaurant owner echoed the importance of personal relationships in accessing local products and stressed that proximity was key in facilitating these networks. The restaurant owner relayed their experience living and working in a rural fishing community in Newfoundland and noted that the proximity to an active fishery allowed them to develop networks and personal relationships with harvesters, which subsequently enhanced their access to locally caught fish. Many respondents viewed this type of relationship with fish harvesters as being very difficult to build from within the urban St. John's area.

While formalized food networks for fish and seafood have, up until very recently, been difficult to form between harvesters, retailers, and consumers, there are nonetheless established informal food networks, particularly in rural communities. One respondent in Petty Harbour noted that she had no trouble accessing local fish in the community due to personal relationships with fish harvesters: 'when the commercial fishery starts up, then that's not a problem for me personally because I have a brother in law who's a commercial fisherman. But if you're not, if you're outside the harbour, you're going to have some problems.... In Petty Harbour, an informal network did seem to take place with regard to cod. One fisher explained: 'Fishermen do it, fishermen take chances and do it for a few extra dollars. That's the way it is in all the communities.' Employees of the Petty Harbour MiniAquarium observed an informal trade in the community, and their location beside the co-operative has positioned the organization as a link between local consumers and tourists that are interested in finding fresh, local seafood.

\section{Education and conservation of culture and nature}

Given that the fisheries in Newfoundland are fundamentally intertwined with place, culture, history, and community, it is no surprise that alternative initiatives are seeking to integrate traditional values and practices. Community actors and restaurants have stepped into try to educate people about food traditions, skills, and the natural environment, in order to create a demand for and interest in locally harvested fish and seafood.

A number of restaurants in St. John's have developed menus that feature not only local products, but also traditional Newfoundland dishes. As well, many have sought to diversify consumer tastes for seafood to include a wider variety of species. 'Fish' is synonymous with cod in Newfoundland, and consumer demand for other species that are caught locally is generally low. While the inadequate access to a diversity of fish species creates barriers, another issue lies in the lack of food skills; people often have limited capabilities and knowledge in preparing fish and seafood other than cod, which restricts what they will purchase. A seafood retailer in St. John's pointed out that this issue did affect what he sold to local consumers, noting that people living in rural coastal areas have more experience and knowledge with regard to preparing a larger variety of fish and seafood.

Seeking to increase food skills among consumers can also help to increase food security and solve food-related 
health issues in the province. Food First NL seeks to emphasize the importance that traditional food skills, such as berry picking, preserving, gardening, and fishing, have played in the past and the ways they can contribute to ensuring food security and self-sufficiency. Equally, Food First NL advocates for the development of food skills and increased access to and availability of local foods, including fish, as means to help mitigate the high prevalence of diet-related health problems in Newfoundland.

The need to build self-sufficiency in Newfoundland's food system was another concerned raised by interview respondents. Young people, in particular, lack knowledge about fishing heritage. A fisher in Petty Harbour asserted that, when he was growing up, fishermen were seen as the heroes in the community, and it was easy to fall into the fishery trap'. The Island Rooms program looks at using food and fisheries as a way to engage youth in the food system and with nature by developing food skills through fishing workshops and by teaching other forms of self-provisioning. With the workforce declining in Newfoundland's fisheries, it is hoped that the project will introduce young people to a possible career in fishing.

A number of interview respondents stressed that there is a disconnection between different food systems actors and the natural environment that must be addressed in Newfoundland, which can be tied to a lack of knowledge about the ecological impacts of food production and fisheries. The Island Rooms and the MiniAquarium are possible avenues to reconnect people to the marine environment through education initiatives related to ecosystem conservation. The Petty Harbour Mini-Aquarium in particular provides an opportunity for people to connect with the local marine environment by learning about, seeing, and handling different aquatic animals, including species that are commercially harvested in Newfoundland such as cod, lobster, and flatfish. By bringing the 'ocean up to eye level', the Mini-Aquarium not only contributes to public education, but also provides fish harvesters with a new means to understand, experience, and appreciate the marine ecosystem on which their livelihoods depend. For instance, the members of the Petty Harbour Fisherman's co-op had never seen a codfish swim and were unaware of some of the characteristics and natural behaviours of the species they fish. In turn, they were also able to share their knowledge and experience of the marine environment with the employees of the aquarium, and there are plans to create a program that would allow visitors to the aquarium to engage with the local fishers.

\section{Discussion}

\section{Developing skills, tastes, and knowledge}

The access to locally sourced fish in Newfoundland is a significant challenge, though there are many potential endeavours that, together, may help in developing fisheries AFNs in the province. Opportunities to develop these alternatives lie in strengthening relations between food systems actors, as well as the connections to nature, place, and Newfoundland culture. The re-emergence of traditional Newfoundland cuisine provides a unique prospect to reconnect with place, culture, and fisheries. Thus, consumers are able to gain an appreciation for and a better knowledge of food that is available locally, which in turn can help create a demand for locally source seafood. The interviews illustrated the integral role that fisheries play in place-making and localization processes, as respondents emphasized the significance of fish within food culture, heritage, and identity in Newfoundland. Cod in particular is a reflection of food preferences and tastes for Newfoundlanders, as well as a manifestation of sense of place, culture, and identity that is established by family, social norms and traditions, economic realities, and landscapes $[13,19,21]$. The efforts of both market and civil society actors help to situate food and fish in particular places and ecologies in Newfoundland by reconnecting individuals with the local marine environment, their fishing heritage, and the local food system.

Market actors play a role in enhancing reconnections in the local food system by engaging with local food cultures and attempting to improve product availability. More specifically, the ways in which restaurateurs in St. John's craft menus that are reflective of seasonality and locally available products can make consumers more aware about the fish and seafood being harvested in Newfoundland. Through this practice, restaurants help to re-instil a pride of place and culture locally and with visitors. Despite the key role that restaurants and chefs can play in promoting locally sourced food and sustainable food systems, their adherence to 'local' is often oriented towards the characteristic of the food itself rather that the processes and conditions through which food is produced [42]. In doing so, they are engaging with weaker conceptions of 'alterity' that neglect broader socio-economic issues. To some extent, this is true of the restaurateurs interviewed, as quality and taste were mentioned as important reasons for preferring locally harvested fish. Nevertheless, most chefs and restaurant owners also expressed a desire to engage in the local food system as a means to support fish harvesters and rural communities, as well as to celebrate local food cultures and traditions.

Encouraging the diversification of the fish species that are consumed locally is a fundamental part of developing 
alternatives in the fisheries and enhancing local economies. However, as previously noted, food skills impact food choices by limiting the foods that individuals are able to prepare and can prevent people from accessing healthy foods and participating in food cultures [43]. In order for fisheries-based AFNs to take root and be sustained in Newfoundland, consumers not only need to be interested in and able to access local fish, but also must have the capacities to prepare it.

The education initiatives put forward by the Island Rooms, Food First NL, and the Mini-Aquarium, in addition to the efforts of St. John's restaurateurs to develop tastes for locally sourced fish, are a means of diversifying local consumer food preferences and enhancing food skills. O'Hara and Stagl [19] assert that food preferences are dynamic and continuously adapting, and it is through education and learning opportunities that aim to increase food knowledge and skills that consumer preferences and values can be altered. This reality is evidenced through the endeavours of the Island Rooms and Food First NL, specifically in their attempts to revitalize self-provisioning skills in order to generate a local food system that is truly sustainable. More specifically, one of the main aims of the Island Rooms is to enable young people to engage in subsistence fishing throughout the province in hopes of creating a more culturally appropriate and secure food system. Subsistence food production and fishing enhance food security in Newfoundland, particularly in rural communities, since people at all income levels are able to access food outside formal markets [28]. Equally, self-provisioning skills allow people to reduce dependency on conventional food supply chains, which lessens the impacts of unforeseen shocks to food supply in Newfoundland, including weather and transportation issues [28].

\section{Challenges to developing fisheries AFNs}

Despite the considerable opportunities and efforts to develop AFNs in Newfoundland's fisheries, the complex political economic structures of the fisheries and food system generate significant challenges. Specifically, fisheries policies at the provincial and federal levels remain highly problematic, even with the recent change in direct sale regulations. Andrée et al. [9] found that in regions where export-oriented food production policies are implemented, the development of AFNs is arduous, since governments prioritize the growth of international markets over stimulating local opportunities. This is the case in Newfoundland's fisheries, where governments at both federal and provincial levels have sought to develop external markets to the detriment of the local one.

The implications of the new regulations for direct fish sales on local markets remain unclear, as many details have yet to be worked out, such as the structure of reporting and monitoring systems. The benefits of this regulatory change for fish harvesters and buyers is equally uncertain, given that the majority of fish harvesters still rely on export markets for most of their catch due to the small local market. This may lead to a more 'hybridized' version of AFNs, in which food producers continue to depend on some conventional aspects of the food system in order for their business to subsist, while waiting for the local demand to expand $[9,44]$. As with the fisheries in Newfoundland, this hybridity can often be the result of policy environments that encourage and incentivize all producers, including those engaging in alternative practices and niche markets, to participate in the conventional supply chain [9]. Direct marketing strategies therefore offer a means to enhance the strength, or 'alternativeness' of AFNs in these environments [45].

Prior to the shift in provincial regulation, the social connections between harvesters and consumers were maintained through informal food networks that have enabled the direct distribution of fish and seafood. Selfprovisioning practices, including the food fishery, are important alternatives to conventional market practices, as well as meaningful facets of Newfoundland heritage. However, as noted, these informal food networks in the fisheries are geographically and socially limited to those near active fisheries and to those who know fish harvesters. AFN literature is limited in its ability to address these informal practices, despite the fact that many of these are, by current definitions, AFNs. Conceptually, AFNs are positioned as a response to conventional food production practices, while informal networks such as those taking place in Newfoundland's fisheries existed before conventional practices were developed. People in many Newfoundland communities have historically bought fish directly from harvesters on the wharf. As one fish harvester put it: 'I mean it was done for year and years and years before all this [provincial legislation] came in.

AFNs that operate as part of informal economies, such as bartering and self-provisioning practices, are culturally significant to Newfoundlanders and will likely remain an important means to access fish, particularly in rural and remote coastal communities. However, these informal practices are not accessible to all, and AFNs that operate within the formal economy also need to be developed. In many instances, formalized alternative food economies are required to enable consumer-producer connections, which can take place in many different ways, such as through direct marketing, local retailers, and restaurants. Newfoundland food systems actors can look elsewhere in Canada, where direct fish sales have legally been allowed for longer periods of time, to draw inspiration in developing fisheries AFNs. Community-supported fisheries (CSFs) are cited as a means for people in Newfoundland, 
particularly in urban areas, to access fresh fish and seafood while enhancing small-scale fisheries and coastal community livelihoods [46]. The CSF model has the capacity to be adapted to a variety of contexts and to meet diverse socio-economic and ecological needs, as long as ethical and environmental concerns are integrated and enacted adequately $[6,18]$. Community and economy are intertwined and integral to the CSF model, thus opening up possibilities for alternative means to managing fisheries resources in a way that builds towards a just and sustainable food system $[6,18]$.

In the light of the legalized direct sales of fish and the increased opportunity to develop strategies such as CSFs, careful consideration must be given to which groups are targeted by AFNs and how these strategies can be made to include a diverse demographic. Many have criticized cases of the practical implementation of AFNs as catering to higher-income and more privileged groups, based on the fact that strategies such as CSA and farmers' markets can prove costly to the consumer [11]. In these cases, central values to AFNs such as social justice, democracy, and inclusivity are neglected, especially as only certain groups have access and are able to participate in alternatives [11]. Many AFNs operate under the assumption that consumers are willing to pay a premium to access sustainably produced and local foods [20]. Conversely, profitability remains a challenge for many alternative food strategies in agricultural contexts, particularly with the goal of attaining a fair price for consumers while ensuring producers' livelihoods [20,47]. These challenges are likely to pose limitations on fisheries AFNs in balancing the need to create an inclusive and affordable model while guaranteeing fish harvesters an adequate income.

Many of the efforts towards creating fisheries AFNs in St. John's tend to cater to higher-income populations, particularly due to the fact that most of the restaurants that are most active in supporting local fish are higher end and quite expensive. Equally, the reliance on marketdriven mechanisms to create more sustainable, localized, and just food systems places the responsibility squarely on the shoulders of consumers, who are expected to vote with their dollar $[6,48]$. These strategies restrict all but those with the economic means from participating in their local food system and having the ability to make food choices based on their values and ethics. These more exclusive AFN strategies risk mirroring the problematic and unequal political economic structures that underpin the conventional food system $[6,11,20]$. In order for systemic changes to take place in the food system, the access to and availability of locally harvested fish needs to be tied to broader food security and food justice goals [6]. The efforts of civil society organizations, such as Food First $\mathrm{NL}$ and the Island Rooms, to highlight the importance of local fish and food in building towards community food security in Newfoundland offer a means to better engage with issues of accessibility and inclusivity in AFNs.

\section{Conclusions}

The question of how alternatives can be developed in Newfoundland's fisheries is best answered by looking at the reconnections taking place within the food system, especially in terms of re-engaging consumers with their food through culture and traditions. The emphasis on relationships and reconnections in AFNs allows for the recognition of the multiple actors involved in building alternative markets and how they relate to one another. This study found that, while fisheries hold important socio-cultural values in Newfoundland, they are primarily valued by government policy for their economic contributions, which has created a significant barrier to building AFNs. Conversely, recognizing these alternate values is key to strengthening the local access and availability of fish, especially those that relate to and build on Newfoundland food cultures and traditions. In fact, the values identified demonstrate that choosing locally harvested fish and seafood is not simply related to personal ideals such as quality, health, and nutrition, but to 'care ethics' related to outward aspirations such as environmental sustainability and enhancing coastal communities.

Furthermore, there is a need for improved access to local fish and seafood in diverse contexts and for many different people in Newfoundland. Along with AFNs, informal food practices enhance the food system in Newfoundland and can provide opportunities to develop alternative practices in the fisheries. More work needs to be done on informal networks in the fisheries, particularly with regard to how these networks and traditional practices in rural coastal communities may be impacted by the new possibility for legal direct sales.

This research contributes to an understanding of how AFNs can emerge and develop in unfavourable policy environments that impede the development of localized markets for fish and seafood. Moreover, while export-oriented fisheries policies are barriers to developing AFNs, this study finds that reconnections are already taking place in the broader food system, and specifically within the fisheries, that aim to create better access to and availability of locally caught fish and seafood in Newfoundland. These reconnections offer a starting point on which to build fisheries AFNs by strengthening existing food systems and economic relations that include ethical and moral values. In other words, there is significant value in 'starting where you are', as it draws attention to the existing community assets and efforts in building towards sustainable and just food systems $[49,50]$. These alternate ways of valuing fisheries are reflective of the diverse 
possibilities in Newfoundland that already exist and that can help to strengthen and create AFNs in the fisheries. In summation, there must be careful consideration of the types of AFNs that are best suited to support community livelihoods, cultural ties, and ecological sustainability in order to create a just and secure food systems.

\section{Abbreviations \\ AFN: alternative food network; DFO: Department of Fisheries and Oceans Canada; DFA: Department of Fisheries and Aquaculture (Provincial govern- ment of Newfoundland and Labrador); FFAW-Unifor: Fish, Food and Allied Workers Union; SJFM: St. John's Farmer's Market.}

\section{Authors' information}

Chloé Poitevin DesRivières is a Ph.D. candidate at Carleton University in Geography with a specialization in Political Economy. Dr. Ratana Chuenpagdee is a professor in the Department of Geography at Memorial University. Dr. Charles Mather is a professor in the Department of Geography at Memorial University.

\section{Authors' contributions}

CPD conceived of the study, participated in its design, performed the primary data collection and analysis, and drafted the manuscript. RC and CM participated in the study design and data analysis and contributed to the writing of the manuscript. All authors read and approved the final manuscript.

\section{Author details}

1 Department of Geography and Environmental Studies, Carleton University, Ottawa, ON, Canada. ${ }^{2}$ Department of Geography, Memorial University of Newfoundland, St. John's, NL, Canada.

\section{Acknowledgements}

This research is part of the Master thesis of the first author and contributes to Too Big to Ignore: Global Partnership for Small-Scale Fisheries Research. The authors would like to express their gratitude to all those who participated in the interviews. We are grateful to Brennan Lowery for his helpful feedback. The authors also thank the reviewers for their useful comments on the manuscript.

\section{Competing interests}

The authors declare that they have no competing interests.

\section{Availability of supporting data}

The primary data used for this study are in the form of interview transcripts and recordings and are not available to share publically other than in the form of publish materials due it containing information that may compromise the privacy/consent of research participants.

\section{Ethical approval and consent to participate}

Ethics approval for the research was granted by the Interdisciplinary Committee on Ethics in Human Research (ICEHR) at Memorial University of Newfoundland. Informed written or oral consent was sought from all interview participants in compliance with ICEHR guidelines.

\section{Funding}

As part of the Too Big to Ignore project, this study was funded by the Social Sciences and Humanities Research Council of Canada (SSHRC; Grant No. 895 -2011-1011).

Received: 23 June 2016 Accepted: 16 March 2017

Published online: 30 March 2017

\section{References}

1. Harris EM. Eat local? Constructions of place in alternative food politics. Geogr Compass. 2010;4(4):355-69. doi:10.1111/j.1749-8198.2009.00298.x.
2. Ponte S. Greener than thou: the political economy of fish ecolabeling and its local manifestations in South Africa. World Dev. 2008;36(1):159-75. doi:10.1016/j.worlddev.2007.02.014

3. Chuenpagdee R, Morgan LE, Maxwell SM, Norse EA, Pauly D. Assessing collateral impacts of fishing methods in US waters. Front Ecol Environ. 2003;1(10):517-24.

4. Lowitt K, Nagy M, Nelson C, Bavington D. Where's the fish? Altern J. 2013;39(4):1-6 (Food and Drink)

5. Loring PA, Gerlach SC, Harrison HL. Seafood as local food: food security and locally caught seafood on Alaska's Kenai Peninsula. J Agric Food Syst Community Dev. 2013:3(3):13-30.

6. Olson J, Clay PM, Pinto da Silva P. Putting the seafood in sustainable food systems. Mar Policy. 2014;43:104-11. doi:10.1016/j.marpol.2013.05.001.

7. Winter M. Embeddedness, the new food economy and defensive localism. J Rural Stud. 2003;19(1):23-32. doi:10.1016/S0743-0167(02)00053-0.

8. Holloway L, Kneafsey M, Cox R, Venn L, Dowler E, Helena T. Beyond the 'alternative'-'conventional' divide? Thinking differently about food production-consumption relationships. In: Maye D, Holloway L, Kneafsey $M$, editors. Alternative food geographies: representation and practice. Bingley: Emerald; 2008. p. 77-93.

9. Andrée P, Dibden J, Higgins V, Cocklin C. Competitive productivism and Australia's emerging "alternative" agri-food networks: producing for farmers' markets in Victoria and beyond. Aust Geogr. 2015;2010(41):307-22. doi:10.1080/00049182.2010.498038.

10. Howard PH. Concentration and power in the food system. London: Bloomsbury; 2016.

11. Guthman J. Bringing good food to others: investigating the subjects of alternative food practice. Cult Geogr. 2008;15:431-47. doi:10.1177/1474474008094315.

12. Campbell LM, Boucquey N, Stoll J, Coppola H, Smith MD. From vegetable box to seafood cooler: applying the community-supported agriculture model to fisheries. Soc Nat Resour. 2014;27(1):88-106. doi:10.1080/08941 920.2013 .842276

13. Dowler E, Kneafsey M, Cox R, Holloway L. "Doing food differently": reconnecting biological and social relationships through care for food. Editor Board Sociol Rev. 2009;57(s2):200-21.

14. Kneafsey M, Cox R, Holloway L, Dowler E, Venn L, Tuomainen H. Reconnecting consumers, producers and food: exploring alternatives. Oxford: Berg Publishers; 2008

15. Lind C. Rumours of a moral economy. Halifax: Fernwood Publishing; 2010.

16. Gibson-Graham JK. Diverse economies: performative practices for "other worlds". Prog Hum Geogr. 2008;32(5):613-32. doi:10.1177/0309132508090821.

17. Sayer A. Moral economy as critique. New Polit Econ. 2007:12(2):261-70. doi:10.1080/13563460701303008.

18. Snyder R, St. Martin K. A fishery for the future: the midcoast fishermen's association and the work of economic being-in-common. In: Roelvink $G$, St. Martin K, Gibson-Graham JK, editors. Making other worlds possible: performing diverse economies. Minneapolis: University of Minnesota Press; 2015. p. 26-52.

19. O'Hara SU, Stagl S. Endogenous preferences and sustainable development. J Socio Econ. 2002;31:511-27.

20. Allen P. Realizing justice in local food systems. Camb J Reg Econ Soc. 2010;3(2):295-308. doi:10.1093/cjres/rsq015.

21. DeLind LB. Of bodies, place, and culture: re-situating local food. J Agric Environ Ethics. 2006;19(2):121-46. doi:10.1007/s10806-005-1803-z.

22. Parkins W, Craig G. Culture and the politics of alternative food networks. Food Cult Soc An Int J Multidiscip Res. 2009;12:77-103. doi:10.2752/1552 80109X368679.

23. Kurlansky M. Cod: a biography of the fish that changed the world. Toronto: Random House Canada; 1997.

24. Schrank WE. The Newfoundland fishery: ten years after the moratorium. Mar Policy. 2005;29(5):407-20. doi:10.1016/j.marpol.2004.06.005.

25. Department of Fisheries and Aquaculture (DFA). Annual Report 2013-14. 2014. http://www.fishaq.gov.nl.ca/publications/pdf/annual_ report_2013_14.pdf.

26. Mather C. From cod to shellfish and back again? The new resource geography and Newfoundland's fish economy. Appl Geogr. 2013;45:402-9. doi:10.1016/j.apgeog.2013.06.009. 
27. Foley P. The political economy of marine stewardship council certification: processors and access in Newfoundland and Labrador's inshore shrimp industry. Agrar Change. 2012;12(2):436-57.

28. Lowitt $K$. Examining fisheries contributions to community food security findings from a household seafood consumption survey on the west coast of Newfoundland. J Hunger Environ Nutr. 2013;8(2):221-41. doi:10.1 080/19320248.2013.786668.

29. Food First NL. Everybody eats: a discussion paper on food security in Newfoundland and Labrador. 2015. http://static1.squarespace. com/static/54d9128be4b0de7874ec9a82/t/56572239e4b0b807738c 5ad0/1448550969272/Everybody+Eats_NL+Discussion+Paper+2015. pdf.

30. Teitelbaum S, Beckley T. Harvested, hunted and home grown: the prevalence of self-provisioning in rural Canada. J Rural Community Dev. 2006:1:114-30.

31. Felt LF, Sinclair PR. "Everyone does it": unpaid work in a rural peripheral region. Work Employ Soc. 1992;6(1):43-64. doi:10.1177/095001709261003.

32. Murphy I, Neis B. Navigating the legislative requirements for fisheriestourism initiatives in Newfoundland and Labrador. 2012. http://www. curra.ca/documents/TCR_Fisheries Tourism_Regulations_Report.pdf.

33. Eric Dunne Consulting Initiatives. Report of the review of the regulations and policy for direct fish sales in Newfoundland. 2010: p. 1-51. http:// www.fishaq.gov.nl.ca/publications/pdf/Direct_Fish_Sales_NL_2010.pdf.

34. Song AM, Chuenpagdee R. A principle-based analysis of multilevel policy areas on inshore fisheries in Newfoundland and Labrador, Canada. In: Jentoft S, Chuenpagdee R, editors. Interactive governance for small-scale fisheries. MARE Publication Series. Vol. 5. Cham: Springer; 2015. p. 435-65. doi:10.1007/978-3-319-17034-3.

35. Department of Finance- Newfoundland \& Labrador Statistics Agency. Population estimates. 2016. http://www.stats.gov.nl.ca/statistics/population/PDF/Population_Estimates_CDCMA.pdf. Accessed 26 Jan 2017.

36. Root Cellars Rock! Local Links. 2014. http://rootcellarsrock.ca/local-links/. Accessed 14 April 2014.

37. Gollner AL. Jeremy Charles: Canada's real top chef. Globe Mail. 2014 http://www.theglobeandmail.com/life/jeremy-charles-canadas-real-topchef/article20495580/. Accessed 1 May 2015.

38. Protected Areas Association of Newfoundland and Labrador. Ancient rights: The protected fishing area of Petty Harbour-Maddox Cove. 1996. http://collections.mun.ca/PDFs/ich_avalon/AncientRightsBooklet.pdf.
39. Cope M. Interviewing. In: Warf B, editor. Encyclopedia of human geography. Thousand Oaks: Sage Publications; 2006. p. 262-63. doi: 10.4135/9781412952422.n163.

40. Mason J. Semi-structured interview. In: Lewis-Beck MS, Bryman A, Liao TM, editors. The SAGE encyclopedia of social science research methods. Vol. 3; Thousand Oaks: Sage Publications; 2004. p. 1020-22. doi:10.4135/9781412950589.

41. Kooiman J, Jentoft S. Meta-governance: values, norms and principles, and the making of hard choices. Public Adm. 2009;87(4):818-36. doi:10.1111/j.1467-9299.2009.01780.x.

42. Inwood SM, Sharp JS, Moore RH, Stinner DH. Restaurants, chefs and local foods: insights drawn from application of a diffusion of innovation framework. Agric Hum Values. 2008;26(3):177-91. doi:10.1007/ s10460-008-9165-6.

43. Stead M, Caraher M, Wrieden W, Longbottom P, Valentine K, Anderson A. Confident, fearful and hopeless cooks: findings from the development of a food-skills initiative. Br Food J. 2004;106(4):274-87. doi:10.1108/00070700410529546.

44. Watts DCH, Ilbery B, Maye D. Making reconnections in agro-food geography: alternative systems of food provision. Prog Hum Geogr. 2005;29(1):22-40. doi:10.1191/0309132505ph526oa.

45. Mount P. Growing local food: scale and local food systems governance. Agric Hum Values. 2011;29(1):107-21. doi:10.1007/s10460-011-9331-0.

46. Neis B, Ommer R. Moving forward: building economically, socially and ecologically resilient fisheries and coastal communities. 2014. http:// www.curra.ca/documents/Revised_CURRA.

47. Galt RE. The moral economy is a double-edged sword: explaining farmers earnings and self-exploitation in community-supported agriculture. Econ Geogr. 2013;89(4):341-65.

48. Konefal J. Environmental movements, market-based approaches, and neoliberalization: a case study of the sustainable seafood movement. Organ Environ. 2012;26(3):336-52. doi:10.1177/1086026612467982.

49. Gibson-Graham JK. Postcapitalist politics. Minneapolis: University of Minnesota Press; 2006. doi:10.1017/CBO9781107415324.004.

50. Harris E. Neoliberal subjectivities or a politics of the possible? Reading for difference in alternative food networks. Area. 2009;41:55-63. doi:10.1111/j.1475-4762.2008.00848.x.

\section{Submit your next manuscript to BioMed Central and we will help you at every step:}

- We accept pre-submission inquiries

- Our selector tool helps you to find the most relevant journal

- We provide round the clock customer support

- Convenient online submission

- Thorough peer review

- Inclusion in PubMed and all major indexing services

- Maximum visibility for your research

Submit your manuscript at www.biomedcentral.com/submit
(OioMed Central 